\title{
Perception of Major Life Events and Personality Trait Change
}

\author{
Peter Haehner ${ }^{1}$, Andrew Rakhshani ${ }^{2}$, Ina Fassbender ${ }^{3}$, Richard E. Lucas ${ }^{2}$, M. Brent \\ Donnellan $^{2}$, and Maike Luhmann ${ }^{1}$ \\ ${ }^{1}$ Department of Psychology, Ruhr University Bochum \\ ${ }^{2}$ Department of Psychology, Michigan State University \\ ${ }^{3}$ Department of Psychology, University of Siegen
}

This paper has been accepted for publication at European Journal of Personality, May 24, 2022. This paper is not the copy of record and may not exactly replicate the final, authoritative version of the article. The final article is available on:

https://doi.org/10.1177/08902070221107973

Haehner, P., Rakhshani, A., Fassbender, I., Lucas, R. E., Donnellan, M. B., \& Luhmann, M. (2022). Perception of major life events and personality trait change. European Journal of Personality. Advance online publication. https://doi.org/10.1177/08902070221107973

Version 3 - May 2022

\section{Author Note}

Peter Haehner (iD) https://orcid.org/0000-0002-3896-6172

Andrew Rakhshani (D) https://orcid.org/0000-0001-6081-1479

Ina Fassbender (iD https://orcid.org/0000-0003-0423-6259

Richard E. Lucas (D) https://orcid.org/0000-0002-7995-3319

Maike Luhmann (DiD https://orcid.org/0000-0001-6211-9304

The study design was preregistered at https://osf.io/pm5xn/. The preregistration of the present analyses, the data, and R scripts can be retrieved from https://osf.io/783px/. We have no known conflict of interest to disclose. Data collection was funded by Pathways to Character Project (sponsored by the John Templeton Foundation and the Arizona State University Foundation), Grant 60699 to Maike Luhmann.

Correspondence concerning this article should be addressed to Peter Haehner, Department of Psychology, Ruhr University Bochum, Universitaetsstr. 150, 44780 Bochum, Germany. Email: peter.haehner@rub.de 


\begin{abstract}
Major life events can trigger personality trait change. However, a clear, replicable pattern of event-related personality trait change has yet to be identified. We examined whether the perception of major life events is associated with personality trait change. Therefore, we assessed young adults' personality traits at five measurement occasions within one year. At the second measurement occasion, we also assessed their perception of a recently experienced major life event using the Event Characteristics Questionnaire. Contrary to our expectations, perceived impact of the event was not associated with the amount of personality trait change, but perceived valence was associated with changes in agreeableness and neuroticism. Exploratory analyses revealed some weak associations between other perceived event characteristics and the amount of personality trait change as well as interactions between perceived event characteristics and event categories in predicting changes in neuroticism. In general, effect sizes were small, and associations depended on the time interval between preevent and post-event personality assessment. Results indicate that perceived event characteristics should be considered when examining event-related personality trait change.
\end{abstract}

Word count: 172

Keywords: major life events, perceived event characteristics, Big Five traits, personality change, valence 


\section{Perception of Major Life Events and Personality Trait Change}

Personality traits are "enduring patterns of thoughts, feelings, and behaviors, that distinguish individuals from one another" (Bleidorn et al., 2018, p. 83). Although personality traits are relatively enduring, they can also change over the lifetime (e.g., Damian et al., 2019; Roberts et al., 2006), and these changes are relevant for various important life outcomes such as job satisfaction or relationship satisfaction (e.g., Hoff et al., 2021; Schwaba et al., 2019; Scollon \& Diener, 2006). Therefore, it is important to understand the causes of personality trait change. One possible environmental cause of personality trait change is the experience of major life events such as graduation, childbirth, or a new employment (Bleidorn et al., 2018). Although several studies have found evidence for personality trait change in reaction to major life events, more research is needed to better understand when and under which circumstances event-related personality trait changes occur (Bleidorn et al., 2020; Denissen et al., 2019). For example, it has been proposed that the way major life events are perceived may be relevant for their effects on psychological outcomes (Bleidorn et al., 2020; Luhmann et al., 2021). Until recently, however, most studies on event-related personality trait change did not assess how people perceive the experienced events or focused only on a single perceived event characteristic (e.g., often the valence of major life events; Kandler \& Ostendorf, 2016; Lüdtke et al., 2011; Vries et al., 2021). The present study aimed for a more comprehensive perspective regarding the associations between the perception of major life events and event-related change in the Big Five personality traits.

\section{Personality Trait Change in the Context of Major Life Events}

Major life events can be defined as “events that are clearly timed, disrupt one's everyday routine, and are perceived as personally significant and memorable by those who experienced them" (Luhmann et al., 2021, p. 634). Personality theories differ in their claims regarding eventrelated personality trait change. While Five-Factor Theory assumes that personality traits are “essentially independent of environmental influences" (McCrae et al., 2000, p. 173), other 
theories suggest that major life events may cause lasting personality trait change. For example, Social Investment Principle of Neo-Socioanalytic Theory suggests that major life events can lead to personality trait change if they change people's social roles and everyday life (Roberts et al., 2005; Roberts \& Nickel, 2017).

Inspired by the literature on subjective well-being, these different perspectives on eventrelated personality trait change have also been described using different set-point models (Ormel et al., 2012; Ormel et al., 2017). The immutable set-point model assumes that people have a biologically determined point of origin for their personality traits (i.e., their set point) and that this set point cannot be changed by environmental influences (similar to the proposal of the Five-Factor Theory). In contrast, the experience-dependent set-point model assumes that the set point is responsive to strong environmental experiences such as major life events. Finally, the mixed set-point model combines both perspectives and assumes that the set point of personality traits has immutable and changeable parts (Ormel et al., 2012; Ormel et al., 2017).

Empirically, several studies found evidence for event-related personality trait changes in line with the experience-dependent or mixed set-point model (for an overview see Bleidorn et al., 2018; Bleidorn et al., 2020). For example, two studies found that neuroticism decreased after experiencing the event "first romantic relationship" (Lehnart et al., 2010; Wagner et al., 2015). However, the effects found for event-related personality trait changes were only small and the results only partly replicated across studies (Bleidorn et al., 2020; Denissen et al., 2019; Löckenhoff et al., 2009). Furthermore, it is unclear why some people show lasting changes in their personality traits after experiencing the same major life event while others do not. Thus, more research is needed to better understand event-related personality trait changes (Bleidorn et al., 2020). 


\section{Considering the Perception of Major Life Events in the Context of Personality Trait}

\section{Change}

Different methods to assess major life events have been used in research on eventrelated personality trait change. Each method provides a specific perspective on these changes. Some studies focused on the simple occurrence of single major life events (e.g., whether someone experienced the first romantic relationship or not; Asselmann \& Specht, 2020; Denissen et al., 2019). Other studies relied on researcher-based classifications of major life events to certain event categories and then, for example, used sum scores of experienced events of a certain category to predict personality trait change (e.g., uncontrollable vs. controllable events, Kandler et al., 2012; or positive vs. negative events, Neeleman, 2003). Both methods provide a more objective assessment of major life events, but they ignore how people subjectively perceive major life events.

Assessing the perception of major life events may be important to better understand event-related personality trait changes for several reasons. First, the same major life event can be perceived quite differently by different individuals; and thus, it can have differential effects on personality trait change (Bleidorn et al., 2020; Luhmann et al., 2021). For example, in a study by Kandler and Ostendorf (2016), participants used the complete range of the valence scale (from very negative to very positive) to describe their subjective experience of the event "separation from spouse". Second, different major life events may have similar effects on personality trait change when they are perceived similarly. For example, a new relationship and a new job may both lead to a decrease in neuroticism when they are perceived as impactful, positive events. Third, assessing how people perceive major life events has been a successful way to explain individual differences in event-related changes in other personality-relevant outcomes including subjective well-being, depressive symptoms, and anxiety (e.g., FassettCarman et al., 2020; Luhmann et al., 2021; Prizmić-Larsen et al., 2020). Thus, assessing 
perceived event characteristics may also be helpful to better understand event-related personality trait change.

\section{Assessment of the Perception of Major Life Events and Existing Empirical Evidence}

There are already a few studies that examined how people perceive major life events in the context of personality trait change. One common way of evaluating the perception of major life events is by using life event checklists that weight the subjective experience of each major life event on a given dimension. We refer to this approach of dimensionally assessing the subjective experience of major life events as the perceived event characteristic approach. For example, with the Life Experience Survey (Sarason et al., 1978), participants rate the positive and negative impact of experienced major life events; then the impact ratings are summed

across all experienced events. These sum scores have been used to explain event-related personality trait change (e.g., Kandler et al., 2012; Lüdtke et al., 2011; Vaidya et al., 2002). For example, Vaidya et al. (2002) and Lüdtke et al. (2011) found that the sum score of negatively perceived events was associated with an increase in neuroticism. This approach has an important limitation, however, as these sum scores confound the effects of the number of experienced major life events with the effects of the perceived event characteristics.

Kandler and Ostendorf (2016) demonstrated that the effects of event occurrence and perceived event characteristics can be separated. They found that the perceived valence but not the mere occurrence of specific major life events such as "religious crisis" or "serious illness or injury" was associated with neuroticism before and after these events. Similarly, Vries et al. (2021) examined the effects of the occurrence and the perceived valence of the major life events "graduating from school" and "moving away from home" on personality trait changes in young adulthood. Again, not the mere occurrence of these events but only their perceived valence was associated with changes in neuroticism and extraversion.

In sum, these studies support the notion that the perception of major life events is important for personality trait changes (and likely even more important than the mere event 
occurrence). However, the mentioned studies considered only one perceived event characteristic (i.e., valence), while other perceived event characteristics such as predictability, emotional significance, and extraordinariness of major life events may be important as well (Vries et al., 2021). Luhmann et al. (2021) developed the Event Characteristics Questionnairea dimensional taxonomy of nine empirically derived perceived event characteristics (valence, impact, predictability, challenge, emotional significance, change in world views, socials status change, external control, and extraordinariness. The idea of this taxonomy is to replace the categorical classification of major life events (and their limitations such as intracategorical variability; Monroe, 2008). Instead, perceived event characteristics should be used to capture psychological meaningful differences in the subjective experience of major life events (Luhmann et al., 2021; Rauthmann et al., 2014). This dimensional taxonomy of perceived event characteristics has already been used to explain event-related changes in subjective well-being, empathy, and prosociality (Fassbender et al., 2021; Luhmann et al., 2021). With the present study, we aimed to examine their utility to explain event-related changes in the Big Five personality traits (irrespective of the categorical classification of major life events).

\section{Hypotheses and Research Questions}

Based on existing empirical evidence and theoretical considerations, we had concrete hypotheses regarding the effects of two perceived event characteristics: valence and impact. Regarding the other seven perceived event characteristics that are assessed with the Event Characteristics Questionnaire, we formulated exploratory research questions.

\section{Research Question 1: Valence}

Several studies using different assessment methods (e.g., researcher-based classifications of positive versus negative events or participants' ratings of the perceived valence) have shown that the valence of major life events is important for personality trait change (Lüdtke et al., 2011; Spinhoven et al., 2011). In general, the results seem to be most consistent for the Big Five personality traits of extraversion and neuroticism (Kandler \& 
Ostendorf, 2016; Lüdtke et al., 2011; Vries et al., 2021): Perceiving events as positive should be associated with a decrease in neuroticism and with an increase in extraversion (Hypothesis 1 and 2).

\section{Research Question 2: Impact}

Regarding the relevance of the perceived event characteristic impact, previous studies suggest that more impactful events lead to more change (Löckenhoff et al., 2009; Vries et al., 2021). For example, Löckenhoff et al. (2009) assumed that prior research on event-related personality trait change was limited by the fact that more and less impactful events were combined using sum scores. Therefore, they focused on extreme adverse events to predict personality trait change, and they indeed found changes in neuroticism, agreeableness, and openness in their study.

Additionally, theories such as Social Investment Principle (Roberts et al., 2005; Roberts \& Nickel, 2017) and Integrative State Process Model (Geukes et al., 2018) suggest that eventrelated personality trait changes occur when a major life event leads to changes in social roles and everyday life. As the perceived event characteristic impact refers to perceived changes in social roles and everyday life, we hypothesized that perceived impact would be associated with the amount of personality trait change ${ }^{1}$ (Hypothesis 3 ).

\section{Research Question 3: Interaction of Impact and Valence}

Based on findings in the context of event-related changes in subjective well-being (Luhmann et al., 2021), we also examined whether perceived valence and impact interact in predicting personality trait change. Luhmann et al. (2021) found that events perceived as

\footnotetext{
${ }^{1}$ For this hypothesis, we focus on the amount of personality trait change since the perceived event characteristic impact captures the perceived extent of changes in social roles and everyday life but not specific role gains or losses. Thus, when examining different major life events that are accompanied with changes in social roles in different directions, perceived impact should only be associated with the amount (i.e., absolute value of) but not with the direction of personality trait change.
} 
negative and impactful were associated with more pronounced changes in subjective well-being than events perceived as negative but not as impactful. Similarly, one could expect that events that are perceived as negative and impactful are associated with stronger increases in neuroticism than events that are perceived as negative but not as impactful. However, since this is rather speculative, we did not formulate hypotheses for this research question.

\section{Research Question 4 and 5: Other Perceived Event Characteristics}

To obtain a comprehensive picture of the relation between perceived event characteristics and personality trait change, we also explored whether the other seven perceived event characteristics assessed with the Event Characteristics Questionnaire (predictability, challenge, emotional significance, change in world views, social status change, external control, and extraordinariness) are associated with personality trait change. Since we did not have concrete hypotheses for these event characteristics, we explored their associations with both the amount and the direction of personality trait change.

\section{Research Question 6: Combining Perceived Event Characteristics and Event Categories}

The previously mentioned research questions focus on the relevance of the perceived event characteristics irrespective of the categorical classification of major life events. However, perceived event characteristics do not only vary across different event categories but also within a certain event category (Kritzler et al., 2021). Therefore, we also explored whether combining perceived event characteristics and information on event categories can explain personality trait change. Therefore, we examined whether there is an interaction between perceived event characteristics and event categories in predicting personality trait changes. Combining both approaches to predict personality trait changes may be useful as they provide different perspectives on major life events. Event categories (e.g., "educational event" or "health-related event") usually describe the content of major life events (i.e., what participants experienced), whereas perceived event characteristics focus on the perceived causes, circumstances, and consequences of major life events. 


\section{The Present Study}

With the present study, we examined the association between the perception of major life events and personality trait change. We extend existing research in two ways: First, we assessed the perception of major life events comprehensively using the dimensional taxonomy developed by Luhmann et al. (2021). Second, we used data from a longitudinal study with five measurement occasions occurring every three months (henceforward referred to as T1 to T5). This study design allows us to better understand the unfolding of the associations between the perceived event characteristics and personality trait change over time. At T2, participants rated their perception of the most significant major life event that they had experienced between $\mathrm{T} 1$ and T2. This allowed us to investigate event-related personality trait change with one pre-event (T1) and four post-event (T2 to T5) assessments of personality traits.

\section{Methods}

This paper is based on data from the What's Next? Study, a longitudinal panel study conducted in 2018 and 2019. Data from this study have previously been analyzed by Fassbender et al. (2021), Haehner et al. (2021), Kritzler et al. (2021), and Luhmann et al. (2021), but none of these publications investigated event-related personality trait change. Data collection of the What's NEXT? Study was approved by local ethics committee of [INSTITUTION BLINDED FOR PEER REVIEW]. The study design was preregistered at [LINK BLINDED FOR PEER REVIEW], and analyses for the present paper were preregistered at https://osf.io/u5m7v?view_only=7a722f24ed0845bbafd26fe4dffe6435. Deviations from this preregistration are summarized in the supplemental material (Table S1).

\section{Procedure}

The What's Next? Study is a five-wave longitudinal study focused on young adulthood since this is a sensitive phase for personality trait change in which major life events occur frequently (Lüdtke et al., 2011; Roberts, 2018). Participants were recruited online via social media or in person, for example, at welcome events at [INSTITUTION BLINDED FOR PEER 
REVIEW]. Participants could take part in voucher raffles after each measurement occasion as a compensation.

Participants first registered for the study. The registration included providing informed consent, an email address, and age verification (minimum age 18 years). After the registration, participants were invited via email to the following five online surveys that were spread over one year (i.e., $0,12,24,36$, and 48 weeks after registration). They were invited to the subsequent measurement occasions regardless of whether they had participated in previous measurement occasions.

At T2, participants freely named the most important major life event that they had experienced since $\mathrm{T} 1$ and rated this event with the Event Characteristics Questionnaire. Furthermore, at each measurement occasion, participants were asked to complete various questionnaires assessing their subjective well-being and personality including the Big Five personality traits (see study-design preregistration for a complete list of questionnaires).

\section{Participants}

A total of 857 people registered to take part in the What's Next? Study. Our sample included individuals who participated at least in $\mathrm{T} 1$ and $\mathrm{T} 2$ so that we have data on the participant's pre-event personality traits (assessed at T1) and on the rating of perceived event characteristics (assessed at T2). As preregistered, we further excluded participants' data from measurement occasions that were completed in less than 10 minutes (40\% of expected duration) and with no or incorrect answers on the instructed response items (see below) to ensure data quality. Finally, only participants who named a major life event at T2 that occurred in the requested time frame (i.e., between T1 and T2) were included in our analyses. Applying these criteria, our final sample consisted of $N=433$ participants ( $76 \%$ female, $93 \%$ with a high school degree). Participants' mean age at T1 was 21.77 years $(S D=4.01)$. 


\section{Measures}

\section{Naming of a Major Life Event and Event Categories (T2)}

At T2, participants freely named the most important major life event they had experienced since T1. Furthermore, participants indicated which life domains were affected by these events (e.g., relationship and partnership, job and applications, or finances). Using information on the free-text descriptions and affected life domains, we categorized the named events into event categories. We created two categorizations with different purposes: a finegrained categorization (35 categories; e.g., starting college, important exam, cease education successfully) and a broad categorization (7 categories; e.g., educational events). The broad categorization led to higher sample sizes for each event category and was created to address Research Question 6. The fine-grained categorization was used to provide more detailed information on the named events. More information regarding our event codings and the frequencies of the event categories can be found in the supplemental material (Table S2 and Table S3).

\section{Event Characteristics Questionnaire (T2)}

Participants were asked to rate the major life event they had experienced with the Event Characteristics Questionnaire (Luhmann et al., 2021; items as in Study 5). The Event Characteristics Questionnaire assesses nine perceived event characteristics: challenge (4 items, e.g., "The event was straining"), change in world views (4 items, e.g., "The event helped me to gain new perspectives"), emotional significance (4 items, e.g., "The event was emotionally significant to me"), external control (4 items, e.g., "Others were able to control the event"), extraordinariness (3 items, e.g., "Few people like me experience such an event in their lives"), impact (4 items, e.g., "The event led to changes in my social, family or work roles"), predictability (4 items, e.g., "I knew in advance that the event would be happening"), social status change (4 items, e.g., "My reputation suffered from the event"), and valence (6 items, e.g., "The event was positive"). All 37 items were answered on a five-point scale ranging from 
1 (not true at all) to 5 (absolutely true) and items were presented in randomized order. We reversed responses if appropriate and calculated mean scores for our analyses.

\section{Big Five Personality Traits (T1 to T5)}

The Big Five Inventory-2 Extra Short Form (German version by Rammstedt et al., 2018; original version by Soto \& John, 2017) was used to assess the Big Five personality traits: conscientiousness (3 items, e.g., "I am somebody who is reliable, can always be counted on"), agreeableness (3 items, e.g., "I am somebody who is compassionate, has a soft heart"), extraversion (3 items, e.g., "I am somebody who is dominant, acts as a leader"), negative emotionality (akin to neuroticism; 3 items, e.g., "I am somebody who tends to be depressed, blue"), and open-mindedness (akin to openness; 3 items, e.g., "I am somebody who is fascinated by art, music, or literature"). Items were rated on a five-point scale ranging from 1 (strongly disagree) to 5 (strongly agree) and items were presented in randomized order. We reversed responses if appropriate and calculated mean scores for descriptive purposes.

\section{Data Analysis}

Analyses were conducted in R (Version 4.0.3). Data and R scripts can be retrieved from https://osf.io/783px/?view_only=4e44e0759d5d47bc94091a21fb746854. The analyses for Research Questions 1 to 5 were preregistered and comprised three steps. First, we checked for longitudinal measurement invariance of the Big Five personality trait measure. Second, we estimated latent change score models using pre-event and post-event personality assessments to obtain estimates of within-person personality trait change. Third, we ran several multilevel models using the within-person personality trait change scores as dependent variables as well as time intervals between the measurement occasions and perceived event characteristics as predictors. Research Question 6 was inspired by the comments of the anonymous reviewers during the revision of this manuscript and therefore not preregistered. For this research question, a slightly different modeling approach was used to test whether it leads to similar results as our analytic approach for Research Questions 1 to 5. 


\section{Testing Longitudinal Measurement Invariance}

To ensure that the Big Five personality traits can be compared between the five measurement occasions, we examined longitudinal measurement invariance using $\mathrm{R}$ packages lavaan (Rosseel, 2012) and semTools (Jorgensen et al., 2020). Separately for each Big Five personality trait, we evaluated configural, metric, and scalar measurement invariance in a stepwise approach. Details on model specification and results are summarized in the supplemental material (Table S4). All Big Five personality traits showed scalar measurement invariance. However, it should be noted that the covariance matrix of latent variables was not positive definite for agreeableness and extraversion: The correlations of some latent variables' (i.e., correlations for a certain personality trait among the measurement occasions) were greater than one. This issue may be a symptom of model misspecification or sampling error (Kolenikov \& Bollen, 2012). Since model fit was good and all confidence intervals of the correlations of the latent variables' included plausible values, we assumed sampling error and the relatively short time interval between the measurement occasions to be the reasons for this issue.

\section{Estimating Individual Personality Trait Change Scores with Latent Change Score Models}

Latent change score models were computed to estimate within-person personality trait change scores. We used latent change score models since they allowed us to estimate personality trait change without accumulation of measurement error when calculating difference scores (McArdle, 2009). For each of the Big Five personality traits, we computed four latent change score models using the pre-event personality assessment (T1) and one of the post-event personality assessments (T2 to T5). Consequently, for each Big Five personality trait, these models provided four latent change scores that indicate personality trait change over 3 months (between T1 and T2), 6 months (T1 and T3), 9 months (T1 and T4), and 12 months (T1 and T5), respectively. This modeling procedure is illustrated in Figure 1A.

We estimated these latent change score models by using the indicator variable method (i.e., fixing the factor loading of the first indicator to one and its mean to zero). Furthermore, 
we set factor loadings and means to be equal across the different measurement occasions ${ }^{2}$ and we allowed correlated residuals for the same repeatedly measured indicators. Regarding the latent variables, the mean and variance of the latent change variable and of the first latent factor (i.e., pre-event personality assessment) were freely estimated, whereas the autoregressive path was fixed to one (see also Figure 1A). We used full information maximum likelihood estimation to address missing data issues.

\section{Examining Perceived Event Characteristics and Personality Trait Change with Multilevel}

\section{Models}

To examine the associations between the perceived event characteristics and personality trait change over different time intervals $(3,6,9$, and 12 months), we computed several multilevel models with time intervals nested in participants. We estimated multilevel models with random intercepts only (i.e., no random slopes) to have overidentified models and to avoid estimation problems. We used Satterthwaite approximated degrees of freedom to evaluate significance of fixed effects as implemented in the R package lmerTest (Kuznetsova et al., 2017). In general, for Research Questions 1 to 5, the multilevel models were computed in a similar way: the personality trait change variables estimated with the latent change score models served as dependent variables; time intervals (treated categorically with four levels; Level 1), one of the perceived event characteristics (Level 2), and their cross-level interactions served as predictors. Examples for the model equations are presented in the supplemental material (Table S5).

Coding and Transformations of the Variables in the Multilevel Models. First, we standardized the perceived event characteristics and the personality trait change variables

\footnotetext{
${ }^{2}$ We used the indicators' factor loadings and intercepts estimated with the latent change score model for T1 and $\mathrm{T} 2$ and restricted the indicators' factor loadings and intercept in the other latent change scores models to these values.
} 
estimated with the latent change score models. The latter were standardized using the $S D$ of the pre-event personality assessment so that personality trait change variables can be interpreted in T1 SD units. Second, for Research Questions 2 and 5, we calculated the absolute values of these standardized personality trait change scores to estimate the amount of personality trait change. Third, we dummy coded the Level-1 predictor time interval since we had no specific hypothesis regarding the functional form of within-person personality trait change for the different time intervals. Using dummy coding, the shortest interval between pre- and post-event personality assessment (3 months; between T1 and T2) served as reference category and the other time intervals $(6,9$, and 12 months) were each represented by one dummy-variable (Figure 1B). This coding allowed us to evaluate whether personality trait change occurred between $\mathrm{T} 1$ and $\mathrm{T} 2$ and whether these changes persisted over longer time intervals.

Modeling Strategy. The multilevel models for Research Questions 1 to 5 differed in two aspects: (1) which perceived event characteristic served as predictor, and (2) whether personality trait change scores with sign or their absolute values served as dependent variable. These differences are summarized in Table 1. To answer our research questions and to test our hypotheses, we used two analyses: model comparisons and estimation of simple slopes.

Model comparisons were conducted as omnibus tests to evaluate whether specific predictors significantly improved model fit for a certain Big Five personality trait. For Research Questions 1, 2, 4, and 5, we compared a model that only included the time interval as predictor with a model that additionally included the perceived event characteristic of interest and its cross-level interactions with the time interval. Similarly, for Research Question 3, we compared models with and without the interaction between valence and impact (see Table 1 for details). If these model comparisons were not significant for a certain Big Five personality trait, the respective event characteristic (or the interaction between valence and impact) did not significantly improve model fit in the prediction of personality trait change. Consequently, no further inspections were made (besides looking at simple slopes as effect size estimates; see 
below). However, if a model comparison was significant, we more closely examined the fixed effects and simple slopes because a significant model comparison could be caused by the main effect of the perceived event characteristic and/or the interaction between that event characteristic and time interval. A significant main effect of a certain perceived event characteristic (e.g., valence for Research Question 1) indicated that there is a significant association between this predictor and personality trait change over 3 months (since " 3 months" was the reference category). Significant cross-level interactions (e.g., between time interval and valence) indicated that the strength of the association between the perceived event characteristic and personality trait change changed when considering longer time intervals between pre-event and post-event personality assessment. For example, for Research Question 1, a significant positive cross-level interaction would indicate that the association between valance and personality trait change becomes more positive over 6,9 , and 12 months compared to a 3-month interval.

Simple Slopes. Simple slopes were estimated using the emtrends-function of the R package emmeans (Lenth, 2021). Simple slopes indicate the association between a certain event characteristic and (the amount of) personality trait change for specific time intervals and served two purposes. First, simple slopes were used as effect size estimates since they can be interpreted in standard deviation units. For example, they indicate how a $1 S D$ increase in perceived impact is related to the amount of personality trait change (in T1 SD units) over 3, 6, 9, and 12 months. Therefore, we estimated simple slopes regardless of the significance of the above-described model comparisons. Second, the statistical significance of these simple slopes indicated whether a perceived event characteristic was significantly associated with personality trait change over 3, 6, 9, and 12 months. However, we only evaluated and interpreted the statistical significance of simple slopes if the above-described model comparisons were significant. As preregistered, we used $\alpha=.05$ as level of significance for our literature-based 
Research Questions 1 to 3 and a more conservative level of significance of $\alpha=.01$ to reduce Type I error inflation for our exploratory Research Questions 4 and 5 (cf. Lakens et al., 2018).

\section{Data Analysis for Research Question 6 (Not Preregistered)}

To examine whether combining event categories and perceived event characteristics can be used to predict personality trait change, a slightly different analysis strategy was used. Using a different analysis strategy for Research Question 6 also allowed us to test whether a similar result pattern regarding the association between perceived event characteristics and personality trait change emerged with different statistical methods.

Modeling Strategy. We computed multilevel models with measurement occasions nested in participants. The most important difference compared to the analyses of Research Questions 1 to 5 is that personality trait scores (instead of personality trait change scores estimated with the latent change score models) served as dependent variables. Personality trait scores were standardized on the pre-event mean and $S D$. First, we included time since the event (in weeks, Time_lin) and a pre-event dummy (Time_pre) as predictors. Second, we included the main effects of the perceived event characteristics (standardized using their grand-mean and $S D$ ) and information on the event category (dummy-coded with "educational events" as reference category) as predictors. Third, we included the cross-level interactions between Time_lin, perceived event characteristics, and event categories. The interactions between Time_lin and the perceived event characteristics and event categories allowed us to evaluate whether perceived event characteristics and/or event categories can explain individual differences in personality trait changes over time. We evaluated the statistical significance of these interactions using $\chi^{2}$-tests as implemented in the Anova-function of the car package (Fox $\&$ Weisberg, 2019). If these tests were significant $(\alpha=.01)$, we inspected the fixed effects. More details on the modeling strategy can be found in the supplemental material.

Comparison to Analysis of Research Questions 1 to 5. Using this modeling strategy allowed to directly test and compare different functional forms of personality trait change over 
time. For example, we tested whether a quadratic time effect improved model fit compared to a linear time effect. This was not the case for any of the Big Five personality traits. However, in contrast to the analysis of Research Questions 1 to 5, this modeling strategy does not allow to test whether the associations between personality trait change and the perceived event characteristics change over time and the amount of personality trait change cannot be estimated within these models.

\section{Results}

\section{Descriptive Statistics}

Descriptive statistics and internal consistencies for all scales are summarized in Table 2. Intercorrelations between all variables are reported in the supplemental material (Table S7 and S8).

\section{Latent Change Score Models}

The primary aim of the latent change score models was to estimate latent change variables that indicate within-person personality trait change over 3, 6, 9, and 12 months. Descriptive statistics of these personality trait change variables are summarized in Table 3: Personality trait change was most pronounced for neuroticism, which on average decreased $0.08 S D$ to $0.27 S D$-units between $\mathrm{T} 1$ and the subsequent measurement occasions. Model fit indices for each latent change score model were acceptable or good (all CFI > .98, TLI > .96, and RMSEA < .05; Schermelleh-Engel et al., 2003; see supplemental material Table S9).

\section{Valence and Personality Trait Change}

To examine whether perceived valence is associated with personality trait change (Research Question 1), we computed multilevel models with the within-person personality change scores with sign as dependent variable and with time interval, perceived valence, and their cross-level interactions as independent variables. We compared these models with a model that included time interval as the sole predictor. As can be seen in Table 4, the inclusion of valence did not improve model fit for extraversion, openness, and conscientiousness. This result 
was inconsistent with Hypothesis 1 that valence is positively associated with changes in extraversion.

However, model comparisons were significant for agreeableness $\left(\chi^{2}(4)=12.49\right.$, $p=.014)$ and neuroticism $\left(\chi^{2}(4)=10.80, p=.029\right)$. Looking at the fixed effects for neuroticism, the main effect for valence was not significant but the cross-level interactions between valence and two time intervals (9 and 12 months) were significant (Table 5). These results indicate that valence is not significantly related to change in neuroticism over 3 months (as reflected in the non-significant main effect for valence), but that the strength of the association between valence and changes in neuroticism significantly changes when considering a 9- or 12-month interval (as reflected in the significant cross-level interactions). To examine how these associations changed, we looked at the simple slopes for neuroticism (Table 4). On a descriptive level, the association between valence and neuroticism switched signs from negative to positive with longer time intervals (Figure 2A). However, simple slopes were not significantly different from zero for any time interval. Thus, results are not in line with Hypothesis 2 (valence is associated with a decrease in neuroticism) but indicate that the association between valence and change in neuroticism is time interval dependent.

For agreeableness, there was a significant main effect for valence, which indicates that valence is related to changes in agreeableness over 3 months $(b=0.020, S E=0.007$, $95 \% \mathrm{CI}=[0.006,0.034], t(1341.43)=2.732, p=.006)$. Considering that this trait in general decreased over the first 3 months, this result means that experiencing positive events instead of negative events is associated with smaller decreases in agreeableness. Perceiving events as $1 S D$ above the mean (i.e., a positive event perception) reduced decreases in agreeableness over 3 months by $0.02 S D$. However, as indicated by the significant cross-level interactions and the confidence intervals of simple slopes, this positive association between valence and change in agreeableness is not significant over 6 and 9 months, but significant again over 12 months 
(Figure 2B). In sum, positive valence of events is associated with less negative changes in agreeableness, but the strength (and significance) of this association is time interval dependent.

\section{Impact and the Amount of Personality Trait Change}

To examine whether the perceived impact of an event is associated with the amount of personality trait change (Research Question 2), we computed multilevel models with the absolute values of the within-person personality trait change variables as dependent variables and with time interval, impact, and their cross-level interactions as independent variables. We again compared these models with a model that only included the time interval as predictor. Since none of these model comparisons were significant (all $p>.085$, Table 6), we concluded that perceived impact is unrelated to the amount of personality trait change — at least for a 1-year time frame. This conclusion is also supported by inspecting the simple slopes that indicate the association between perceived impact and the amount of personality trait change over 3, 6, 9, and 12 months. As can be seen in Table 6, these simple slopes fluctuate unsystematically around zero. Thus, results are inconsistent with Hypothesis 3 according to which higher perceived impact is associated with a higher amount of personality trait change.

\section{Interaction of Valence and Impact}

To examine whether the interaction between perceived valence and impact predicts personality trait change (Research Question 3), we computed multilevel models that included the interaction of these two perceived event characteristics and compared them with multilevel models without this interaction. Since none of these model comparisons were significant for any of the Big Five personality traits (all $p>.091$, Table 7), we concluded that the interaction of perceived valence and impact does not predict personality trait change in our sample.

\section{Other Perceived Event Characteristics and Personality Trait Change}

To examine whether the other perceived event characteristics assessed with the Event Characteristics Questionnaire were associated with personality trait change (Research Question 4), we used the within-person personality trait change variables with sign as dependent 
variables. We compared a model that only included time intervals as predictors with models that additionally included one of the other perceived event characteristics and its cross-level interactions with time. Results for these model comparisons are summarized in Table 8. No model comparison reached our stricter threshold of significance $(\alpha=.01)$. Consequently, the other perceived event characteristics did not predict personality trait change in our sample.

\section{Other Perceived Event Characteristics and Amount of Personality Trait Change}

To examine whether the other perceived event characteristics assessed with the Event Characteristics Questionnaire were associated with the amount of personality trait change (Research Question 5), we computed multilevel models with the absolute value of personality trait change as dependent variables and time intervals, one perceived event characteristic, and their cross-level interactions as independent variables. We again compared these models with models that included time intervals as sole predictors. Results are summarized in Table 9. Based on our stricter level of significance of $\alpha=.01$ for Research Questions 4 and 5, there were two statistically significant effects for agreeableness, one for neuroticism, and one for openness. Simple slopes for these models with significant effects are summarized in Table 10. Fixed effects for these models and simple slopes for all other models can be found in the supplemental material (Tables S11 and S12).

For agreeableness, change in world views and external control were associated with the amount of personality trait change. Simple slopes indicate a similar result pattern for both perceived event characteristics: While these two perceived event characteristics were either positively related or unrelated to the amount of personality trait change over 3, 6 and 9 months, they became negatively associated with the amount of change in agreeableness over 12 months. Over 12 months, perceiving events as a $1 S D$ above the mean in external control and change in world views were each associated with a $0.02 S D$ decrease in the amount of personality trait change. 
For neuroticism and openness, predictability was related to the amount of personality trait change. However, the result pattern differed for these two personality traits. For neuroticism, predictability was negatively associated with the amount of personality trait change. Over the 9-month interval, perceiving events as $1 S D$ above the mean in predictability was associated with a $0.05 S D$ decrease in the amount of change in neuroticism. For openness, perceived predictability was positively associated with the amount of personality trait change. Over the 3 months interval, perceiving events as $1 S D$ above the mean in predictability was associated with a $0.02 S D$ increase in the amount of change in openness. To sum up, there were some associations between the other perceived event characteristics assessed with the Event Characteristics Questionnaire and the amount of personality trait change, but these associations were small and time-interval dependent.

\section{Combining Perceived Event Characteristics and Event Categories (Not Preregistered)}

To examine whether the combination of perceived event characteristics and event categories predicts personality trait changes (Research Question 6), we computed multilevel models with personality traits scores (and not change or amount of change in personality traits) as dependent variables. Time since the event (in weeks), perceived event characteristics, and event categories as well as their interactions served as predictors. In these models, the crosslevel interactions between time and the perceived event characteristics and/or event categories were the effects of interest.

For neuroticism, two significant cross-level interactions were found: Social status change and valence showed a significant three-way interaction with time and event category (Table 11). In general, these three-way interactions indicate that the association between a perceived event characteristics and (linear) personality trait change over time differs between event categories. In particular, for social status change, fixed effects indicated that the association between social status change and change in neuroticism was significantly more positive within the event categories "living situation" $(b=0.011, S E=0.004,99 \% \mathrm{CI}=[0.001$, 
0.021], $t(1379.90)=2.77, p=.006)$ and "health-related events" $(b=0.010, S E=0.004$, $99 \% \mathrm{CI}=[0.001,0.020], t(1374.72)=2.87, p=.004)$ than within the reference event category “educational event". To illustrate the meaning of these cross-level interactions with an example: People who experienced an educational event and who perceived this event as social status threatening (1SD above the mean) decreased in their neuroticism by $0.31 S D$ over 1 year, whereas people who experienced a health-related event and perceived this event as social status threatening increased in their neuroticism by $0.47 S D$ over 1 year. Similarly, within the event category "occupational events" the association between valence and change in neuroticism was significantly stronger than in the event category "educational event" ( $b=0.012, S E=0.004$, $99 \% \mathrm{CI}=[0.001,0.022], t(1389.14)=2.72, p=.007)$. For the other Big Five personality traits, no significant cross-level interactions were found (Table S14 to S17).

\section{Discussion}

We used a longitudinal dataset with five measurement occasions spread over 1 year to examine whether and how the perception of major life events was related to personality trait change. Perceived valence of events was significantly related to changes in agreeableness and neuroticism. Furthermore, there were a few, small associations between the other perceived event characteristics assessed with the Event Characteristics Questionnaire and the amount of personality trait change. For example, change in world views and external control were negatively related to the amount of change in agreeableness. However, all mentioned relationships were time interval dependent. That is, the size, significance, and/or sign of the associations changed when considering different time intervals between pre- and post-event assessment. Additionally, we found some interactions between the perceived event characteristics and event categories in predicting changes in neuroticism. However, contrary to our hypotheses, we neither found significant associations between perceived impact and the amount of personality trait change nor significant interactions between perceived impact and valence in predicting personality trait change. Nonetheless our findings indicate that 
considering the perception of major life events may be useful to better understand event-related personality trait change.

\section{Perceived Valence and Personality Trait Change}

Perceived valence was associated with changes in agreeableness and neuroticism, but not with changes in openness, conscientiousness, or extraversion. Thus, our findings were not in line with Hypothesis 1 that positive valence predicts an increase in extraversion. Furthermore, they were also not in line with our Hypothesis 2 (positive valence predicts a decrease in neuroticism) since the association between valence and changes in neuroticism switched its sign over time. Furthermore, our exploratory analyses for Research Question 6 suggest that the association between perceived valence and changes in neuroticism may differ across event categories. That is, perceived valence was more strongly associated with changes in neuroticism for occupational events than for educational events.

Although the findings for neuroticism were not in line with our hypothesis, they are worth a closer inspection. The fact that the association between perceived valence and changes in neuroticism was time interval dependent leads to the question why this association was changing over time. One explanation may be that neuroticism returns to its set point after an event (Ormel et al., 2017): Negative events might cause short-term increases in neuroticism; but this effect may fade over time, eventually returning to a baseline - a result that is consistent with all three types of set-point models (immutable, experience-dependent, and mixed set-point models). In this context, one must address the question whether changes in personality traits over 3 months that fade over time qualify as "personality trait change". As discussed by Roberts et al. (2017), such short-term changes in personality trait measures may just reflect state-level variance in these measures. To further explore this explanation, it would be interesting to investigate how the association between perceived valence and neuroticism develops over even longer time frames (e.g., multiple years) and whether and how personality states change in the same time frame. 
For agreeableness, positive events were associated with positive changes in this trait, but the size (and statistical significance) of this association were again time-interval dependent. Positive changes in agreeableness after positive events are in line with several studies that used perceived valence ratings in sum scores (e.g., Lüdtke et al., 2011; Vaidya et al., 2002). However, there are also studies that did not find such an effect (e.g., Specht et al., 2011). Since our study provides initial evidence that the associations between the perceived event characteristics and personality trait change are time-interval dependent, such diverging findings might be explained by the fact that event-related changes in agreeableness were examined over different time intervals in the respective studies (e.g., Vaidya et al., 2002: 2.5 years; Specht et al., 2011: 4 years). However, it should also be noted that in the analyses of Research Question 6, perceived valence was not associated with (linear) changes in agreeableness, questioning the robustness of this association. Thus, a replication of our findings in future research is needed.

\section{Perceived Impact and Personality Trait Change}

We did not find any evidence for our hypotheses that perceived impact was associated with the amount of personality trait change or that the interaction between perceived impact and valence predicted personality trait change. These hypotheses were based on theoretical claims that changes in social roles and everyday life should lead to personality trait change (Geukes et al., 2018; Roberts et al., 2005; Roberts \& Nickel, 2017).

A possible explanation of our findings may be the difference between perceived and actual changes. For example, post-traumatic growth research has shown that perceived changes in social relationships and character growth do not necessarily correspond to actual changes in these domains (Jayawickreme \& Blackie, 2014). Similarly, perceived changes in social roles and everyday life may only partly correspond to their actual changes and assessing perceived impact may thus not be sufficient to predict personality trait change. Indeed, testing the correspondence between perceived and actual changes in social roles and everyday life as well as their joint contribution to predict personality trait change would be an interesting question 
for future research. For this purpose, a longitudinal study that incorporates experience sampling assessments (maybe combined with mobile sensing) to capture actual changes in everyday life would be needed (Bleidorn et al., 2020). Furthermore, investment in new social roles should be assessed to fully capture the prediction of Social Investment Principle (Lodi-Smith \& Roberts, 2007).

\section{Other Perceived Event Characteristics}

In our exploratory analyses, the other perceived event characteristics beyond impact and valence did not predict the direction of personality trait change, however, there were some associations with the amount of personality trait change. Perceived predictability was positively associated with the amount of change in openness over 3 months and negatively associated with the amount of change in neuroticism over 9 months. Furthermore, change in world views and external control were negatively associated with the amount of change in agreeableness over 12 months. Finally, in the analyses for Research Question 6, there were association between social status change and changes in neuroticism which differed across event categories.

Given the exploratory nature of these analyses, further investigations should be conducted before attributing too much importance to the specific associations. Nonetheless, these findings allow some general conclusions. First, they highlight once again that the associations between the perceived event characteristics and personality trait change depend on the time interval. Second, the fact that only perceived valence predicted the direction of personality trait change might indicate that valence is a central property of major life events. Third, although perceived valence of an event is an important perceived characteristic, it was not the only one associated with personality trait change. Thus, considering multiple perceived event characteristics may provide a more comprehensive picture of event-related personality trait change (Vries et al., 2021).

In general, the perceived event characteristics were most closely related to changes in agreeableness and neuroticism in our study. A possible reason why the associations were 
strongest for these two personality traits may be that the major life events that were experienced by our participants particularly promote changes in agreeableness and neuroticism. The events that were experienced most frequently were events such as starting college, new friendship, relocation, and starting a new job. All these events require establishing new social relationships - a typical developmental task for young adults (Hutteman et al., 2014). To establish new social relationships, an increase in agreeableness and a decrease in neuroticism may thus be adaptive (Roberts \& Nickel, 2017; Specht, 2017). An alternative explanation for the fact that the perceived event characteristics were most closely related to changes in agreeableness and neuroticism may be the nature of the perceived event characteristics. The perceived event characteristics may in general be most suitable to predict changes in agreeableness and neuroticism. For example, they were most strongly associated with these traits in a cross-sectional study (Rakhshani et al., 2021).

\section{Effect Sizes of Perceived Event Characteristics for Predicting Personality Trait Change}

In general, the found associations between the perceived event characteristics and personality trait change were small: A $1 S D$ difference in a certain perceived event characteristic was at maximum associated with a $0.05 S D$ change in personality traits. To contextualize this effect size, the associations found between the perceived event characteristics and personality trait change are about as strong as the associations between the perceived event characteristics and changes in empathy and prosociality (Fassbender et al., 2021) but only about half the size of the association between the perceived event characteristics and changes in subjective wellbeing (Luhmann et al., 2021). Furthermore, the associations found are approximately as strong as effect sizes in studies that examined event-related personality trait change by assessing major life events through life event checklists or changes in demographic information (e.g., Denissen et al., 2019; Wagner et al., 2015; see Table S18 and S19 for more information on effect sizes in other studies). Thus, although we used a different perspective on major life events by considering the perception of major life events, the result pattern was similar: The effect of 
major life events on personality trait change is small and a single event might have a weaker effect than initially assumed (Bleidorn et al., 2020; Vries et al., 2021).

\section{Considering Perceived Event Characteristics in the Context of Personality Trait Change}

In our analyses regarding Research Questions 1 to 5, we examined whether perceived event characteristics are related to personality trait change irrespective of the categorical classification of events. Addressing this question is relevant as the perceived event characteristics have been proposed as alternative to the categorical classification of major life events (Luhmann et al., 2021). In line with this idea, we found a few, weak associations between the perceived event characteristics and personality trait changes irrespective of event categories.

However, the results of Research Question 6 indicate that additionally including information on event categories may be useful to better understand event-related personality trait changes. As outlined in the introduction, event categories usually provide descriptive information on the "content" of major life events (i.e., what the participants experienced), while perceived event characteristics provide information on perceived causes, consequences, and circumstances of major life events. For future research, it might be best to combine (1) the assessment of a wide range of perceived event characteristics (as used in our study; maybe enriched with even more specific perceived event characteristics regarding perceived changes in certain trait demands); and (2) detailed descriptions of the content of major life events (i.e., moving beyond the assessment of broad event categories as in our study). Assessing major life events more comprehensively may thus help to explain event-related personality trait changes. A possible way to combine these two kinds of event information may be their assessment in the recently proposed Longitudinal Experience-Wide Association Studies (Bleidorn et al., 2020). This term describes a research design to examine personality trait change by using multiple measurement occasions, assessing a broad array of life experiences, and employing a range of change-sensitive methods. Hence, major life events can and should be captured 
comprehensively by assessing their perceived characteristics as well as detailed information on the event content (e.g., including implications for everyday life).

Examining perceived event characteristics may also be relevant in the context of missed events (i.e., the non-occurrence of an expected event). Missed events have been discussed as potential cause of changes in subjective well-being, personality traits, and mental health (Luhmann et al., 2014; Luhmann et al., 2020). There is initial evidence that missed positive events may be related to decreases in mental health and subjective well-being. In this context, examining individual differences in the expected characteristics (e.g., expected impact, expected emotional significance, and expected valence) of missed events may help to better understand individual differences in reactions to these missed events.

\section{Limitations and Future Directions}

The present investigation had several limitations. First, our study was based on a highly educated, predominantly female sample recruited in a democratic Western industrialized country (Germany). Consequently, it remains a question for future research whether the associations found between perceived event characteristics and personality trait change generalize to other cultural backgrounds. For example, major life events are not equally frequent in different cultures (Ngo \& Le, 2007). One might expect that this frequency influences the ratings of some perceived event characteristics (e.g., extraordinariness, predictability) and possibly also their associations with personality trait change.

Second, the participants in our study rated the experienced major life events as quite impactful (since participants rated their most important event of the past 3 months), rather positive, and relatively normative (as indicated by the descriptive statistics of the perceived event characteristics valence and extraordinariness). Although all perceived event characteristics still showed substantial variability, our results possibly depend on the sampled events and the associated perceived event characteristics. One factor that is closely related to the sampled events and the associated perceived event characteristics is the life phase of our 
participants. In this study, we used a sample of young adults as this life phase is a sensitive phase for personality trait change in which major life events occur frequently (Lüdtke et al., 2011; Roberts, 2018). For this life phase, the sampled events seem to be quite representative (e.g., starting college, relocation, or break up with partner; see frequencies reported by Lüdtke et al., 2011). However, during other life phases (e.g., older adulthood), other major life events will occur more frequently (e.g., retirement, widowhood, becoming a grandparent). Consequently, future research should address the question whether the associations found can be replicated in other age groups as well.

Third, in Research Question 6, we combined information on perceived event characteristics and event categories. We did this using a broad classification of events to increase the sample size for each event category. However, using such a broad classification relatively different major life events are combined to one category (e.g., in our case the event "end of a relationship" and "divorce of parents" were both classified as social events). For future research, more detailed information on the event content should be used for a more comprehensive picture of major life events.

Fourth, with five measurement occasions spread over one year, we were able to examine personality trait change on a rather short time scale compared to other studies (Bleidorn et al., 2020). Examining this shorter time frame was interesting because personality traits may change quickly (Roberts et al., 2017). However, it remains unclear how lasting the observed personality trait change was or whether other event-related changes would occur in the long run. Therefore, an optimal study would combine both: multiple measurement occasions within the first year after a major life event and then additional measurement occasions in the following years (Luhmann et al., 2014).

\section{Conclusion}

Major life events are a possible cause for personality trait change. However, effects are small and results of previous studies are at least partly heterogeneous (Bleidorn et al., 2018; 
Specht, 2017). We aimed for a better understanding of these effects by considering how major life events were perceived. Perceived event characteristics, in particular perceived valence, were related to personality trait change, but these associations were small and time interval dependent. Nonetheless, considering the perception of major life events in context of personality trait change may help to further clarify a complex puzzle of inconsistent and small associations. 


\section{References}

Asselmann, E., \& Specht, J. (2020). Till death do us part: Transactions between losing one's spouse and the Big Five personality traits. Journal of Personality, 88(4), 659-675. https://doi.org/10.1111/jopy.12517

Bleidorn, W., Hopwood, C. J., Back, M. D., Denissen, J. J., Hennecke, M., Jokela, M., Kandler, C., Lucas, R. E., Luhmann, M., Orth, U., Roberts, B. W., Wagner, J., Wrzus, C., \& Zimmermann, J. (2020). Longitudinal Experience-Wide Association Studies - A framework for studying personality change. European Journal of Personality, 34(3), 285-300. https://doi.org/10.1002/per.2247

Bleidorn, W., Hopwood, C. J., \& Lucas, R. E. (2018). Life events and personality trait change. Journal of Personality, 86(1), 83-96. https://doi.org/10.1111/jopy.12286

Damian, R. I., Spengler, M [Marion], Sutu, A., \& Roberts, B. W. (2019). Sixteen going on sixty-six: A longitudinal study of personality stability and change across 50 years. Journal of Personality and Social Psychology, 117(3), 674-695. https://doi.org/10.1037/pspp0000210

Denissen, J. J. A., Luhmann, M., Chung, J. M., \& Bleidorn, W. (2019). Transactions between life events and personality traits across the adult lifespan. Journal of Personality and Social Psychology, 116(4), 612-633. https://doi.org/10.1037/pspp0000196

Fassbender, I., Haehner, P., Buecker, S., \& Luhmann, M. (2021). Perceived characteristics of life events - short-term changes in prosociality and empathy? European Journal of Personality. Advance online publication. https://doi.org/10.1177/08902070211031762

Fassett-Carman, A. N., DiDomenico, G. E., Steiger, J. von, \& Snyder, H. R. (2020). Clarifying stress-internalizing associations: Stress frequency and appraisals of severity and controllability are differentially related to depression-specific, anxiety-specific, and transdiagnostic internalizing factors. Journal of Affective Disorders, 260, 638645. https://doi.org/10.1016/j.jad.2019.09.053

Fox, J., \& Weisberg, S. (2019). An R Companion to Applied Regression (Third). Sage. https://socialsciences.mcmaster.ca/jfox/Books/Companion/

Geukes, K., van Zalk, M., \& Back, M. D. (2018). Understanding personality development. International Journal of Behavioral Development, 42(1), 43-51. https://doi.org/10.1177/0165025416677847

Haehner, P., Kritzler, S., Fassbender, I., \& Luhmann, M. (2021). Stability and change of perceived characteristics of major life events. Journal of Personality and Social Psychology. Advance online publication. https://doi.org/10.1037/pspp0000394

Hoff, K. A., Einarsdóttir, S., Chu, C., Briley, D. A., \& Rounds, J. (2021). Personality changes predict early career outcomes: Discovery and replication in 12-year longitudinal studies. Psychological Science, 32(1), 64-79. https://doi.org/10.1177/0956797620957998

Hutteman, R., Hennecke, M., Orth, U., Reitz, A. K., \& Specht, J. (2014). Developmental Tasks as a Framework to Study Personality Development in Adulthood and Old Age. European Journal of Personality, 28(3), 267-278. https://doi.org/10.1002/per.1959

Jayawickreme, E., \& Blackie, L. E. R. (2014). Post-traumatic Growth as Positive Personality Change: Evidence, Controversies and Future Directions. European Journal of Personality, 28(4), 312-331. https://doi.org/10.1002/PER.1963

Jorgensen, T. D., Pornprasertmanit, S., Schoemann, A. M., \& Rosseel, Y. (2020). semTools: Useful tools for structural equation modeling. https://CRAN.Rproject.org/package $=$ semTools 
Kandler, C., Bleidorn, W., Riemann, R., Angleitner, A., \& Spinath, F. M. (2012). Life events as environmental states and genetic traits and the role of personality: A longitudinal twin study. Behavior Genetics, 42(1), 57-72. https://doi.org/10.1007/s10519-0119491-0

Kandler, C., \& Ostendorf, F. (2016). Additive and Synergetic Contributions of Neuroticism and Life Events to Depression and Anxiety in Women. European Journal of Personality, 30(4), 390-405. https://doi.org/10.1002/per.2065

Kolenikov, S., \& Bollen, K. A. (2012). Testing negative error variances. Sociological Methods \& Research, 41(1), 124-167. https://doi.org/10.1177/0049124112442138

Kritzler, S., Rakhshani, A., Terwiel, S., Fassbender, I., Donnellan, M. B., Lucas, R. E., \& Luhmann, M. (2021). How are common major life events perceived? Exploring differences between and variability of different typical event profiles and raters. PsyArXiv. https://doi.org/10.31234/osf.io/fncz3

Kuznetsova, A., Brockhoff, P. B., \& Christensen, R. H. B. (2017). 1merTest Package: Tests in linear mixed effects models. Journal of Statistical Software, 82(13). https://doi.org/10.18637/jss.v082.i13

Lakens, D., Adolfi, F. G., Albers, C. J., Anvari, F., Apps, M. A. J., Argamon, S. E., Baguley, T., Becker, R. B., Benning, S. D., Bradford, D. E., Buchanan, E. M., Caldwell, A. R., van Calster, B., Carlsson, R., Chen, S.-C., Chung, B., Colling, L. J., Collins, G. S., Crook, Z., . . Z Zwaan, R. A. (2018). Justify your alpha. Nature Human Behaviour, 2(3), 168-171. https://doi.org/10.1038/s41562-018-0311-X

Lehnart, J., Neyer, F. J., \& Eccles, J. (2010). Long-term effects of social investment: The case of partnering in young adulthood. Journal of Personality, 78(2), 639-670. https://doi.org/10.1111/j.1467-6494.2010.00629.x

Lenth, R. V. (2021). emmeans: Estimated marginal means, aka least-squares means. https://CRAN.R-project.org/package=emmeans

Löckenhoff, C. E., Terracciano, A., Patriciu, N. S., Eaton, W. W., \& Costa, P. T. (2009). Selfreported extremely adverse life events and longitudinal changes in five-factor model personality traits in an urban sample. Journal of Traumatic Stress, 22(1), 53-59. https://doi.org/10.1002/jts.20385

Lodi-Smith, J., \& Roberts, B. W. (2007). Social investment and personality: A meta-analysis of the relationship of personality traits to investment in work, family, religion, and volunteerism. Personality and Social Psychology Review, 11(1), 68-86. https://doi.org/10.1177/1088868306294590

Lüdtke, O., Roberts, B. W., Trautwein, U., \& Nagy, G. (2011). A random walk down university avenue: Life paths, life events, and personality trait change at the transition to university life. Journal of Personality and Social Psychology, 101(3), 620-637. https://doi.org/10.1037/a0023743

Luhmann, M., Buecker, S., Kaiser, T., \& Beermann, M. (2020). Nothing going on? Exploring the role of missed events in changes in subjective well-being and the Big Five personality traits. Journal of Personality. Advance online publication. https://doi.org/10.1111/jopy.12539

Luhmann, M., Fassbender, I., Alcock, M., \& Haehner, P. (2021). A dimensional taxonomy of perceived characteristics of major life events. Journal of Personality and Social Psychology, 121(3), 633-668. https://doi.org/10.1037/pspp0000291

Luhmann, M., Orth, U., Specht, J., Kandler, C., \& Lucas, R. E. (2014). Studying changes in life circumstances and personality: It's about time. European Journal of Personality, 28(3), 256-266. https://doi.org/10.1002/per.1951 
McArdle, J. J. (2009). Latent variable modeling of differences and changes with longitudinal data. Annual Review of Psychology, 60, 577-605. https://doi.org/10.1146/annurev.psych.60.110707.163612

McCrae, R. R., Costa, P. T., Ostendorf, F., Angleitner, A., Hřebíčková, M., Avia, M. D., Sanz, J., Sánchez-Bernardos, M. L., Kusdil, M. E., Woodfield, R., Saunders, P. R., \& Smith, P. B. (2000). Nature over nurture: Temperament, personality, and life span development. Journal of Personality and Social Psychology, 78(1), 173-186. https://doi.org/10.1037/0022-3514.78.1.173

Monroe, S. M. (2008). Modern approaches to conceptualizing and measuring human life stress. Annual Review of Clinical Psychology, 4, 33-52. https://doi.org/10.1146/annurev.clinpsy.4.022007.141207

Neeleman, J. (2003). Positive life change and remission of non-psychotic mental illness A competing outcomes approach. Journal of Affective Disorders, 76(1-3), 69-78. https://doi.org/10.1016/S0165-0327(02)00068-X

Ngo, H. M., \& Le, T. N. (2007). Stressful life events, culture, and violence. Journal of Immigrant and Minority Health, 9(2), 75-84. https://doi.org/10.1007/s10903-0069018-6

Ormel, J., Riese, H [Harriëtte], \& Rosmalen, J. G. M. (2012). Interpreting neuroticism scores across the adult life course: Immutable or experience-dependent set points of negative affect? Clinical Psychology Review, 32(1), 71-79. https://doi.org/10.1016/j.cpr.2011.10.004

Ormel, J., VonKorff, M., Jeronimus, B. F., \& Riese, H [H.]. (2017). Set-Point Theory and personality development: Reconciliation of a paradox. In J. Specht (Ed.), Personality development across the lifespan (pp. 117-137). Academic Press.

Prizmić-Larsen, Z., Kaliterna-Lipovčan, L., Larsen, R., Brkljačić, T., \& Brajša-Žganec, A. (2020). The Role of Flourishing in Relationship between Positive and Negative Life Events and Affective Well-Being. Applied Research in Quality of Life, 15(5), 14131431. https://doi.org/10.1007/s11482-019-09743-y

Rakhshani, A., Lucas, R. E., Donnellan, M. B., Fassbender, I., \& Luhmann, M. (2021). Personality traits and perceptions of major life events. European Journal of Personality, 089020702110458. https://doi.org/10.1177/08902070211045825

Rammstedt, B., Danner, D., Soto, C. J., \& John, O. P. (2018). Validation of the short and extra-short forms of the Big Five Inventory-2 (BFI-2) and their German adaptations. European Journal of Psychological Assessment, 36(1), 149-161. https://doi.org/10.1027/1015-5759/a000481

Rauthmann, J. F., Gallardo-Pujol, D., Guillaume, E. M., Todd, E., Nave, C. S., Sherman, R. A., Ziegler, M., Jones, A. B., \& Funder, D. C. (2014). The Situational Eight DIAMONDS: A taxonomy of major dimensions of situation characteristics. Journal of Personality and Social Psychology, 107(4), 677-718. https://doi.org/10.1037/a0037250

Roberts, B. W. (2018). A revised sociogenomic model of personality traits. Journal of Personality, 86(1), 23-35. https://doi.org/10.1111/jopy.12323

Roberts, B. W., Luo, J., Briley, D. A., Chow, P. I., Su, R., \& Hill, P. L. (2017). A systematic review of personality trait change through intervention. Psychological Bulletin, 143(2), 117-141. https://doi.org/10.1037/bul0000088

Roberts, B. W., \& Nickel, L. B. (2017). A critical evaluation of the Neo-Socioanalytic Model of personality. In J. Specht (Ed.), Personality development across the lifespan (pp. 157-177). Academic Press. 
Roberts, B. W., Walton, K. E., \& Viechtbauer, W. (2006). Patterns of mean-level change in personality traits across the life course: A meta-analysis of longitudinal studies. Psychological Bulletin, 132(1), 1-25. https://doi.org/10.1037/0033-2909.132.1.1

Roberts, B. W., Wood, D., \& Smith, J. L. (2005). Evaluating Five Factor Theory and social investment perspectives on personality trait development. Journal of Research in Personality, 39(1), 166-184. https://doi.org/10.1016/j.jrp.2004.08.002

Rosseel, Y. (2012). lavaan: An R Package for structural equation modeling. Journal of Statistical Software, 48(2). https://doi.org/10.18637/jss.v048.i02

Sarason, I. G., Johnson, J. H., \& Siegel, J. M. (1978). Assessing the impact of life changes: Development of the Life Experiences Survey. Journal of Consulting and Clinical Psychology, 46(5), 932-946. https://doi.org/10.1037/0022-006X.46.5.932

Schermelleh-Engel, K., Moosbrugger, H., \& Müller, H. (2003). Evaluating the fit of structural equation models: Tests of significance and descriptive goodness-of fit measures. Methods of Psychological Research, 23-74.

Schwaba, T., Robins, R. W., Grijalva, E., \& Bleidorn, W. (2019). Does Openness to Experience matter in love and work? Domain, facet, and developmental evidence from a 24-year longitudinal study. Journal of Personality, 87(5), 1074-1092. https://doi.org/10.1111/jopy.12458

Scollon, C. N., \& Diener, E. (2006). Love, work, and changes in extraversion and neuroticism over time. Journal of Personality and Social Psychology, 91(6), 1152-1165. https://doi.org/10.1037/0022-3514.91.6.1152

Soto, C. J., \& John, O. P. (2017). Short and extra-short forms of the Big Five Inventory-2: The BFI-2-S and BFI-2-XS. Journal of Research in Personality, 68, 69-81. https://doi.org/10.1016/j.jrp.2017.02.004

Specht, J. (2017). Personality development in reaction to major life events. In J. Specht (Ed.), Personality development across the lifespan (pp. 341-356). Academic Press.

Specht, J., Egloff, B., \& Schmukle, S. C. (2011). Stability and change of personality across the life course: The impact of age and major life events on mean-level and rank-order stability of the Big Five. Journal of Personality and Social Psychology, 101(4), 862882. https://doi.org/10.1037/a0024950

Spinhoven, P., Roelofs, K., Hovens, J. G., Elzinga, B. M., van Oppen, P., Zitman, F. G., \& Penninx, B. W. (2011). Personality, Life Events and the Course of Anxiety and Depression. European Journal of Personality, 25(6), 443-452. https://doi.org/10.1002/per.808

Vaidya, J. G., Gray, E. K., Haig, J., \& Watson, D. (2002). On the temporal stability of personality: Evidence for differential stability and the role of life experiences. Journal of Personality and Social Psychology, 83(6), 1469-1484. https://doi.org/10.1037/0022-3514.83.6.1469

Vries, J. H. de, Spengler, M [Maik], Frintrup, A., \& Mussel, P. (2021). Personality development in emerging adulthood-How the perception of life events and mindset affect personality trait change. Frontiers in Psychology, 12, Article 671421. https://doi.org/10.3389/fpsyg.2021.671421

Wagner, J., Becker, M., Lüdtke, O., \& Trautwein, U. (2015). The first partnership experience and personality development. Social Psychological and Personality Science, 6(4), 455-463. https://doi.org/10.1177/1948550614566092 


\section{Table 1}

Summary of the Multilevel Models for Research Questions 1 to 5

\begin{tabular}{|c|c|c|c|}
\hline RQ & $\begin{array}{l}\text { Predictor } \\
\text { of interest }\end{array}$ & $\begin{array}{l}\text { Dependent variable: } \\
\text { Personality change }\end{array}$ & Model comparison \\
\hline 1 & Valence & With sign & $\begin{array}{l}\text { A: } \text { Time }^{\mathrm{a}} \\
\text { B: } \text { Time }^{\mathrm{a}}+\text { Valence }+ \text { Time }^{\mathrm{a}} \times \text { Valence }\end{array}$ \\
\hline 2 & Impact & Absolute value & $\begin{array}{l}\text { A: } \text { Time }^{\text {a }} \\
\text { B: } \text { Time }^{\text {a }}+\text { Impact }+ \text { Time }^{\text {a }} \times \text { Impact }\end{array}$ \\
\hline 3 & $\begin{array}{l}\text { Impact } \times \\
\text { Valence }\end{array}$ & With sign & $\begin{array}{l}\text { A: } \text { Time }^{\mathrm{a}}+\text { Impact }+ \text { Valence }+ \text { Time }^{\mathrm{a}} \times \text { Impact }+ \\
\quad \text { Time }^{\mathrm{a}} \times \text { Valence } \\
\text { B: } \text { Time }^{\mathrm{a}}+\text { Impact }+ \text { Valence }+ \text { Time }^{\mathrm{a}} \times \text { Impact }+ \\
\text { Time }^{\mathrm{a}} \times \text { Valence }+ \text { Impact } \times \text { Valence }+ \\
\text { Time }^{\mathrm{a}} \times \text { Valence } \times \text { Impact }\end{array}$ \\
\hline 4 & ECQ_other & With sign & $\begin{array}{l}\text { A: } \text { Time }^{\mathrm{a}} \\
\text { B: } \text { Time }^{\mathrm{a}}+\text { ECQ_other }+ \text { Time }^{\mathrm{a}} \times \mathbf{E C Q} \text { _other }\end{array}$ \\
\hline 5 & ECQ_other & Absolute value & $\begin{array}{l}\text { A: } \text { Time }^{\mathrm{a}} \\
\text { B: Time } \\
\text { a }+ \text { ECQ_other }+ \text { Time }^{\mathrm{a}} \times \text { ECQ_other }\end{array}$ \\
\hline
\end{tabular}

Note. For each research question, we conducted model comparisons (Model A vs. Model B) to evaluate whether a certain perceived event characteristic or the interaction between impact and valence improved model fit. In particular, we tested whether the fixed effects depicted in bold improve model fit. If these model comparisons were significant for a certain Big Five personality trait, we evaluated significance of single fixed effects. As the modelling strategy for Research Question 6 was different, it is not included in this table. More details on the analyses for Research Question 6 can be found in the supplemental material. RQ = research question; ECQ_other = one of the other perceived event characteristics assessed with the Event Characteristics Questionnaire (predictability, challenge, emotional significance, change in world views, socials status change, external control, and extraordinariness).

${ }^{a}$ Time interval was treated categorically. The 3-month interval served as reference category; the intervals 6, 9, and 12 months were each represented by one dummy variable. 
Table 2

Descriptive Statistics and Internal Consistencies for the Big Five Personality Traits and the Nine Perceived Event Characteristics

\begin{tabular}{|c|c|c|c|c|c|c|c|c|c|c|c|c|c|c|c|c|c|c|c|c|}
\hline \multirow[t]{2}{*}{ Variables } & \multicolumn{4}{|c|}{$\mathrm{T} 1$} & \multicolumn{4}{|c|}{$\mathrm{T} 2$} & \multicolumn{4}{|c|}{$\mathrm{T} 3$} & \multicolumn{4}{|c|}{$\mathrm{T} 4$} & \multicolumn{4}{|c|}{ T5 } \\
\hline & $N$ & $M$ & $S D$ & $\alpha$ & $N$ & $M$ & $S D$ & $\alpha$ & $N$ & $M$ & $S D$ & $\alpha$ & $N$ & $M$ & $S D$ & $\alpha$ & $N$ & $M$ & $S D$ & $\alpha$ \\
\hline Neuroticism & 433 & 3.13 & 0.86 & .64 & 433 & 3.1 & 0.86 & .68 & 343 & 3.02 & 0.87 & .69 & 299 & 3.01 & 0.84 & .68 & 293 & 2.96 & 0.85 & .67 \\
\hline Extraversion & 433 & 3.09 & 0.82 & .62 & 433 & 3.08 & 0.78 & .63 & 343 & 3.06 & 0.79 & .66 & 299 & 3.06 & 0.78 & .65 & 293 & 3.14 & 0.75 & .58 \\
\hline Agreeableness & 433 & 3.68 & 0.77 & .55 & 433 & 3.65 & 0.73 & .53 & 342 & 3.68 & 0.77 & .62 & 299 & 3.64 & 0.78 & .65 & 293 & 3.68 & 0.75 & .62 \\
\hline Openness & 433 & 3.68 & 0.74 & .51 & 433 & 3.67 & 0.71 & .51 & 343 & 3.65 & 0.73 & .45 & 299 & 3.71 & 0.71 & .50 & 293 & 3.73 & 0.72 & .51 \\
\hline Conscientiousness & 433 & 3.46 & 0.84 & .61 & 433 & 3.39 & 0.82 & .62 & 343 & 3.46 & 0.78 & .61 & 299 & 3.44 & 0.81 & .63 & 293 & 3.46 & 0.86 & .67 \\
\hline Challenge & & & & & 433 & 3.21 & 1.15 & .87 & & & & & & & & & & & & \\
\hline Change in world views & & & & & 433 & 2.72 & 0.88 & .76 & & & & & & & & & & & & \\
\hline Emotional significance & & & & & 433 & 3.83 & 0.91 & .83 & & & & & & & & & & & & \\
\hline External control & & & & & 433 & 2.56 & 1.08 & .85 & & & & & & & & & & & & \\
\hline Extraordinariness & & & & & 433 & 2.20 & 0.93 & .83 & & & & & & & & & & & & \\
\hline Impact & & & & & 433 & 3.83 & 0.91 & .75 & & & & & & & & & & & & \\
\hline Predictability & & & & & 433 & 3.53 & 1.23 & .92 & & & & & & & & & & & & \\
\hline Social status change & & & & & 433 & 1.30 & 0.57 & .86 & & & & & & & & & & & & \\
\hline Valence & & & & & 433 & 3.97 & 1.23 & .96 & & & & & & & & & & & & \\
\hline
\end{tabular}

Note. The perceived event characteristics were assessed at T2 only. The Big Five personality traits were assessed at each measurement occasion (T1: pre-event personality trait assessment, T2-T5: post-event personality trait assessments). 
Table 3

Descriptive Statistics for the Within-Person Personality Trait Change Variables Over 3, 6, 9, and 12 Months Estimated with the Latent Change

Score Models

\begin{tabular}{|c|c|c|c|c|c|c|c|c|c|c|c|c|c|c|c|c|c|c|c|c|}
\hline \multirow[t]{2}{*}{ Personality trait } & \multicolumn{5}{|c|}{3 months (T1 and T2) } & \multicolumn{5}{|c|}{6 months (T1 and T3) } & \multicolumn{5}{|c|}{9 months (T1 and T4) } & \multicolumn{5}{|c|}{12 months (T1 and T5) } \\
\hline & $M$ & $S D$ & Min & Max & $d$ & $M$ & $S D$ & Min & Max & $d$ & $M$ & $S D$ & Min & $\operatorname{Max}$ & $d$ & $M$ & $S D$ & Min & Max & $d$ \\
\hline Agreeableness & -0.03 & 0.13 & -0.42 & 0.35 & -0.04 & -0.03 & 0.05 & -0.25 & 0.10 & -0.04 & -0.02 & 0.07 & -0.29 & 0.29 & -0.03 & 0.02 & 0.17 & -0.78 & 0.52 & 0.02 \\
\hline Conscientiousness & -0.08 & 0.13 & -0.61 & 0.33 & -0.09 & -0.02 & 0.14 & -0.48 & 0.54 & -0.02 & -0.03 & 0.16 & -0.66 & 0.68 & -0.03 & -0.06 & 0.18 & -0.70 & 0.75 & -0.07 \\
\hline Extraversion & -0.02 & 0.10 & -0.29 & 0.33 & -0.03 & -0.03 & 0.08 & -0.29 & 0.29 & -0.04 & 0.00 & 0.09 & -0.25 & 0.38 & 0.01 & 0.06 & 0.10 & -0.23 & 0.46 & 0.07 \\
\hline Neuroticism & -0.07 & 0.31 & -1.01 & 0.72 & -0.08 & -0.14 & 0.28 & -1.10 & 0.88 & -0.16 & -0.15 & 0.41 & -1.56 & 1.59 & -0.17 & -0.21 & 0.34 & -1.53 & 1.12 & -0.24 \\
\hline Openness & -0.01 & 0.16 & -0.41 & 0.50 & -0.01 & -0.04 & 0.07 & -0.25 & 0.22 & -0.06 & 0.04 & 0.09 & -0.33 & 0.41 & 0.05 & 0.04 & 0.09 & -0.47 & 0.44 & 0.05 \\
\hline
\end{tabular}

Note. Personality trait change variables were estimated over 3, 6, 9, and 12 months using T1 and one of the post-event personality assessments (T2-T5). $d$ indicates the mean of the within-person personality trait change variables that were standardized using the $\mathrm{T} 1 S D$ of the respective personality trait. 


\section{Table 4}

Results for Research Question 1: Associations of Valence and Personality Trait Change

\begin{tabular}{lcccccc}
\hline Personality trait & \multicolumn{2}{c}{ Model comparison } & \multicolumn{3}{c}{ Simple slopes } \\
\cline { 2 - 7 } & $\chi^{2}(d f)$ & $p$ & 3 months $[95 \% \mathrm{CI}]$ & 6 months $[95 \% \mathrm{CI}]$ & 9 months $[95 \% \mathrm{CI}]$ & 12 months $[95 \% \mathrm{CI}]$ \\
\hline Agreeableness & $12.49(4)$ & $\mathbf{. 0 1 4}$ & $\mathbf{0 . 0 2 0}[\mathbf{0 . 0 0 6 , 0 . 0 3 4}]$ & $0.002[-0.012,0.017]$ & $0.010[-0.005,0.024]$ & $\mathbf{0 . 0 2 0}[\mathbf{0 . 0 0 6 , 0 . 0 3 4}]$ \\
Conscientiousness & $1.66(4)$ & .797 & 0.007 & 0.004 & -0.004 & 0.004 \\
Extraversion & $6.69(4)$ & .153 & -0.001 & -0.004 & -0.012 & -0.007 \\
Neuroticism & $10.80(4)$ & $\mathbf{. 0 2 9}$ & $-0.036[-0.073,0.001]$ & $-0.009[-0.046,0.028]$ & $0.021[-0.016,0.058]$ & $0.008[-0.029,0.045]$ \\
Openness & $5.03(4)$ & .284 & -0.009 & -0.008 & -0.015 & -0.012 \\
\hline
\end{tabular}

Note. To test whether the perceived valence was associated with personality trait change (Research Question 1), we computed several model comparisons. Model comparisons

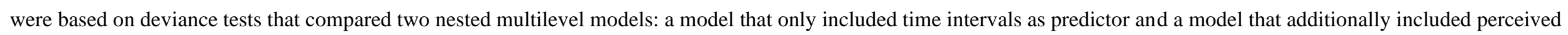
valence and the cross-level interaction with the time intervals as predictors. Significant model comparisons and significant simple slopes based on a level of significance of $\alpha=.05$ are depicted in bold. Simple slopes indicate the associations between perceived valence and change in a certain personality trait over 3,6 , 9 , and 12 months. Confidence intervals of simple slopes (presented in square brackets) are only given if model comparison for the respective trait was significant. 
Table 5

Fixed Effects for Multilevel Models Including Perceived Valence as Predictor and Change in Agreeableness and Neuroticism as Dependent Variable

\begin{tabular}{|c|c|c|c|c|c|c|c|c|c|c|}
\hline \multirow[t]{2}{*}{ Predictor } & \multicolumn{5}{|c|}{ Agreeableness } & \multicolumn{5}{|c|}{ Neuroticism } \\
\hline & $\begin{array}{l}\text { Coefficient } \\
{[95 \% \mathrm{CI}]}\end{array}$ & $S E$ & $d f$ & $t$ & $p$ & $\begin{array}{c}\text { Coefficient } \\
{[95 \% \mathrm{CI}]}\end{array}$ & $S E$ & $d f$ & $t$ & $p$ \\
\hline (Intercept) & $\begin{array}{c}-0.045 \\
{[-0.059,-0.030]}\end{array}$ & 0.007 & 1341.43 & -6.077 & $<.001$ & $\begin{array}{c}-0.079 \\
{[-0.116,-0.042]}\end{array}$ & 0.019 & 949.14 & -4.205 & $<.001$ \\
\hline Time_6M & $\begin{array}{c}0.001 \\
{[-0.016,0.018]}\end{array}$ & 0.009 & 1293 & 0.138 & .890 & $\begin{array}{c}-0.086 \\
{[-0.122,-0.050]}\end{array}$ & 0.018 & 1293 & -4.667 & $<.001$ \\
\hline Time_9M & $\begin{array}{c}0.014 \\
{[-0.003,0.031]}\end{array}$ & 0.009 & 1293 & 1.667 & .096 & $\begin{array}{c}-0.090 \\
{[-0.125,-0.054]}\end{array}$ & 0.018 & 1293 & -4.874 & $<.001$ \\
\hline Time_12M & $\begin{array}{c}0.068 \\
{[0.051,0.085]}\end{array}$ & 0.009 & 1293 & 7.852 & $<.001$ & $\begin{array}{c}-0.165 \\
{[-0.201,-0.129]}\end{array}$ & 0.018 & 1293 & -9.003 & $<.001$ \\
\hline Valence & $\begin{array}{c}0.020 \\
{[0.006,0.034]}\end{array}$ & 0.007 & 1341.43 & 2.732 & .006 & $\begin{array}{c}-0.036 \\
{[-0.073,0.001]}\end{array}$ & 0.019 & 949.14 & -1.924 & .055 \\
\hline Time_6M $\times$ Valence & $\begin{array}{c}-0.018 \\
{[-0.035,-0.001]}\end{array}$ & 0.009 & 1293 & -2.053 & .040 & $\begin{array}{c}0.028 \\
{[-0.008,0.063]}\end{array}$ & 0.018 & 1293 & 1.496 & .135 \\
\hline Time_9M $\times$ Valence & $\begin{array}{c}-0.011 \\
{[-0.027,0.006]}\end{array}$ & 0.009 & 1293 & -1.222 & .222 & $\begin{array}{c}0.057 \\
{[0.021,0.093]}\end{array}$ & 0.018 & 1293 & 3.096 & .002 \\
\hline Time_12M $\times$ Valence & $\begin{array}{c}0.000 \\
{[-0.017,0.017]}\end{array}$ & 0.009 & 1293 & -0.012 & .990 & $\begin{array}{c}0.044 \\
{[0.008,0.080]}\end{array}$ & 0.018 & 1293 & 2.399 & .017 \\
\hline
\end{tabular}

Note. We tested the association between perceived valence and change in agreeableness and neuroticism over different time frames. Time intervals were dummy coded using the shortest interval (3 months, between T1 and T2) as reference category. These models indicate whether the perceived valence predicts change in agreeableness and neuroticism over 3 months (main effect of valence) and whether the strength of this association changes when considering longer time intervals (cross-level interactions between time and valence). We used Satterthwaite approximated degrees of freedom to evaluate significance of fixed effects. Significant fixed effects $(\alpha=.05)$ are depicted in bold. Time_6M =6-month interval (between T1 and T3); Time_9M = 9-month interval (between T1 and T4); Time_12M = 12-month interval (between T1 and T5). 


\section{Table 6}

Results for Research Question 2: Associations Between Perceived Impact and the Amount of Personality Trait Change

\begin{tabular}{lcccccc}
\hline \multirow{2}{*}{ Personality trait } & \multicolumn{3}{c}{ Model comparison } & \multicolumn{5}{c}{ Simple slopes } \\
\cline { 2 - 7 } & $\chi^{2}(d f)$ & $p$ & 3 months & 6 months & 9 months & 12 months \\
\hline Agreeableness & $8.19(4)$ & .085 & 0.001 & -0.000 & -0.001 & -0.014 \\
Conscientiousness & $1.29(4)$ & .863 & 0.003 & 0.004 & 0.007 & 0.001 \\
Extraversion & $5.76(4)$ & .218 & -0.004 & 0.003 & 0.002 & -0.005 \\
Neuroticism & $1.43(4)$ & .840 & 0.001 & 0.006 & -0.011 & 0.004 \\
Openness & $2.35(4)$ & .671 & 0.001 & 0.005 & -0.003 & -0.003 \\
\hline
\end{tabular}

Note. To test whether the perceived impact was associated with the amount of personality trait change (Research Question 2), we computed one model comparison for each Big Five personality trait. Model comparisons were based on deviance tests that compared two nested multilevel models: a model that only included time intervals as predictors and a model that additionally included perceived impact and the cross-level interaction with the time intervals as predictors. For all Big Five personality traits, model comparisons were not significant $(\alpha=.05)$ indicating that perceived impact is not associated with the amount of personality trait change. Simple slopes indicate the associations between perceived impact and the amount of change in a certain personality trait over 3 , 6,9 , and 12 months. 


\section{Table 7}

Results for Research Question 3: Interaction of Impact and Valence

\begin{tabular}{lcc}
\hline \multirow{2}{*}{ Personality trait } & \multicolumn{2}{c}{ Model comparison } \\
\cline { 2 - 3 } & $\chi^{2}(d f)$ & $p$ \\
\hline Agreeableness & $5.91(4)$ & .206 \\
Conscientiousness & $5.03(4)$ & .285 \\
Extraversion & $1.98(4)$ & .739 \\
Neuroticism & $7.52(4)$ & .111 \\
Openness & $8.01(4)$ & .091 \\
\hline
\end{tabular}

Note. To test whether the interaction between perceived valence and impact was associated with personality trait change (Research Question 3), we computed several model comparisons. Model comparisons were based on deviance tests that compared two nested multilevel models: with and without the interaction of perceived valence and impact. Non-significant model comparisons $(\alpha=.05)$ indicate that the interaction of valence and impact is not improving model estimation for the respective trait. 


\section{Table 8}

Results of Model Comparisons for Research Question 4: The Other Perceived Event Characteristics and Personality Trait Change

\begin{tabular}{lccccccccccc}
\hline \multirow{2}{*}{ Perceived event characteristic } & \multicolumn{2}{c}{ Agreeableness } & \multicolumn{2}{c}{ Conscientiousness } & \multicolumn{2}{c}{ Extraversion } & \multicolumn{2}{c}{ Neuroticism } \\
\cline { 2 - 9 } & $\chi^{2}(d f)$ & $p$ & $\chi^{2}(d f)$ & $p$ & $\chi^{2}(d f)$ & $p$ & $\chi^{2}(d f)$ & $p$ & $\chi^{2}(d f)$ & $p$ \\
\hline Challenge & $0.77(4)$ & .942 & $7.74(4)$ & .101 & $2.89(4)$ & .577 & $8.03(4)$ & .091 & $10.12(4)$ & .038 \\
Change in world views & $1.29(4)$ & .864 & $5.76(4)$ & .218 & $2.49(4)$ & .647 & $4.33(4)$ & .363 & $4.96(4)$ & .292 & .29 \\
Emotional significance & $3.80(4)$ & .434 & $1.84(4)$ & .765 & $0.64(4)$ & .958 & $1.21(4)$ & .877 & $10.15(4)$ & .038 \\
External control & $1.08(4)$ & .897 & $3.04(4)$ & .551 & $2.19(4)$ & .701 & $4.79(4)$ & .310 & $6.88(4)$ & .142 \\
Extraordinariness & $9.77(4)$ & .045 & $3.51(4)$ & .477 & $4.84(4)$ & .304 & $6.28(4)$ & .179 & $2.62(4)$ & .623 \\
Predictability & $12.78(4)$ & .012 & $6.27(4)$ & .180 & $9.28(4)$ & .054 & $2.69(4)$ & .612 & $11.86(4)$ & .018 \\
Social status change & $13.04(4)$ & .011 & $2.68(4)$ & .612 & $8.13(4)$ & .087 & $8.92(4)$ & .063 & $1.72(4)$ & .787 \\
\hline
\end{tabular}

Note. To test whether the other perceived event characteristics were associated with personality trait change (Research Question 4), we computed several model comparisons

Model comparisons were based on deviance tests that compared two nested multilevel models: a model that only included time intervals as predictors and a model that

additionally included one of the other perceived event characteristics and its cross-level interaction with time intervals as predictors. Non-significant model comparisons indicate that the respective event characteristics is not improving model estimation. Based on our stricter level of significance for Research Question 4 ( $\alpha=.01$ ), none of the model comparisons was significant. 
Table 9

Results of Model Comparisons for Research Question 5: The Other Perceived Event Characteristics and the Amount of Personality Trait Change

\begin{tabular}{|c|c|c|c|c|c|c|c|c|c|c|}
\hline \multirow[t]{2}{*}{ Perceived event characteristic } & \multicolumn{2}{|c|}{ Agreeableness } & \multicolumn{2}{|c|}{ Conscientiousness } & \multicolumn{2}{|c|}{ Extraversion } & \multicolumn{2}{|c|}{ Neuroticism } & \multicolumn{2}{|c|}{ Openness } \\
\hline & $\chi^{2}(d f)$ & $p$ & $\chi^{2}(d f)$ & $p$ & $\chi^{2}(d f)$ & $p$ & $\chi^{2}(d f)$ & $p$ & $\chi^{2}(d f)$ & $p$ \\
\hline Challenge & $1.53(4)$ & .822 & $1.99(4)$ & .737 & $3.22(4)$ & .522 & $4.65(4)$ & .325 & $1.48(4)$ & .831 \\
\hline Emotional significance & $5.97(4)$ & .201 & $4.03(4)$ & .403 & $0.59(4)$ & .964 & $8.26(4)$ & .082 & $1.93(4)$ & .749 \\
\hline External control & $18.68(4)$ & .001 & $6.47(4)$ & .167 & $2.41(4)$ & .660 & $3.83(4)$ & .429 & $8.16(4)$ & .086 \\
\hline Predictability & $6.93(4)$ & .140 & $0.94(4)$ & .919 & $2.17(4)$ & .705 & $17.94(4)$ & .001 & $13.32(4)$ & .010 \\
\hline Social status change & $1.52(4)$ & .823 & $5.38(4)$ & .251 & $6.47(4)$ & .166 & $0.34(4)$ & .987 & $3.34(4)$ & .503 \\
\hline
\end{tabular}

Note. To test whether the other perceived event characteristics were associated with the amount of personality trait change (Research Question 5), we computed several model comparisons Model comparisons were based on deviance tests that compared two nested multilevel models: a model that only included time intervals as predictors and a model that additionally included one of the other perceived event characteristics and its cross-level interaction with the time intervals as predictors. Non-significant model comparisons indicate that the respective perceived event characteristics is not improving model estimation. Significant model comparisons based on our stricter level of significance for Research Question $5(\alpha=.01)$ are depicted in bold. 


\section{Table 10}

Simple Slopes for Research Question 5 for all Models with Significant Model Comparisons

\begin{tabular}{|c|c|c|c|c|c|}
\hline Predictor & Dependent variable & 3 months $[99 \% \mathrm{CI}]$ & 6 months $[99 \% \mathrm{CI}]$ & 9 months $[99 \% \mathrm{CI}]$ & 12 months $[99 \% \mathrm{CI}]$ \\
\hline \multirow[t]{2}{*}{ Change in world views } & Agreeableness & 0.011 & -0.003 & $>-0.001$ & -0.016 \\
\hline & & {$[-0.002,0.024]$} & {$[-0.015,0.010]$} & {$[-0.013,0.012]$} & {$[-0.029,-0.003]$} \\
\hline External control & & {$[-0.012,0.013]$} & {$[-0.012,0.013]$} & {$[-0.016,0.009]$} & {$[-0.034,-0.008]$} \\
\hline Predictability & Neuroticism & -0.028 & -0.028 & -0.054 & -0.024 \\
\hline \multirow[t]{2}{*}{ Predictability } & Openness & 0.016 & 0.002 & $>-0.001$ & $>-0.001$ \\
\hline & & {$[0.004,0.028]$} & {$[-0.010,0.014]$} & {$[-0.012,0.012]$} & {$[-0.012,0.012]$} \\
\hline
\end{tabular}

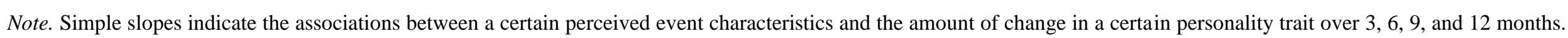

Significant simple slopes $(\alpha=.01)$ are depicted in bold. 


\section{Table 11}

Results of Models for Research Question 6 for Neuroticism: Perceived Event Characteristics, Event Categories, and Personality Change

\begin{tabular}{|c|c|c|c|c|c|c|}
\hline \multirow[t]{2}{*}{$\begin{array}{l}\text { Perceived event } \\
\text { characteristic }\end{array}$} & \multicolumn{2}{|c|}{ Time_lin $\times$ Event Category } & \multicolumn{2}{|c|}{$\begin{array}{c}\text { Time_lin } \times \text { Perceived Event } \\
\text { Characteristic }\end{array}$} & \multicolumn{2}{|c|}{$\begin{array}{l}\text { Time_lin } \times \text { Event Category } \times \\
\text { Perceived Event Characteristic }\end{array}$} \\
\hline & $\chi^{2}(d f)$ & $p$ & $\chi^{2}(d f)$ & $p$ & $\chi^{2}(d f)$ & $p$ \\
\hline Change in world views & $6.70(6)$ & .350 & $0.57(1)$ & .448 & $2.42(6)$ & .877 \\
\hline Emotional significance & $7.24(6)$ & .299 & $1.32(1)$ & .250 & $1.11(6)$ & .981 \\
\hline Extraordinariness & $5.47(6)$ & .485 & $1.67(1)$ & .196 & $3.19(6)$ & .784 \\
\hline Impact & $7.67(6)$ & .264 & $0.74(1)$ & .390 & $5.90(6)$ & .434 \\
\hline Predictability & $7.00(6)$ & .321 & $0.10(1)$ & .750 & $7.40(6)$ & .285 \\
\hline Social status change & $6.52(6)$ & .367 & $5.17(1)$ & .023 & $19.12(6)$ & .004 \\
\hline
\end{tabular}

Note. Results of multilevel models that used neuroticism as dependent variables and time (Time_lin), event categories, and perceived event characteristics as predictors. Depicted are the results of the cross-level interactions between time, event categories, and perceived event characteristics as these effects indicate whether event categories and/or perceived event characteristics moderate (linear) personality trait change. Significant effects $(\alpha=.01)$ are depicted in bold. 


\section{Figure 1}

Illustration of Our Modelling Procedure: Latent Change Score Models (Panel A) and Data Structure for Multilevel Models (Panel B)

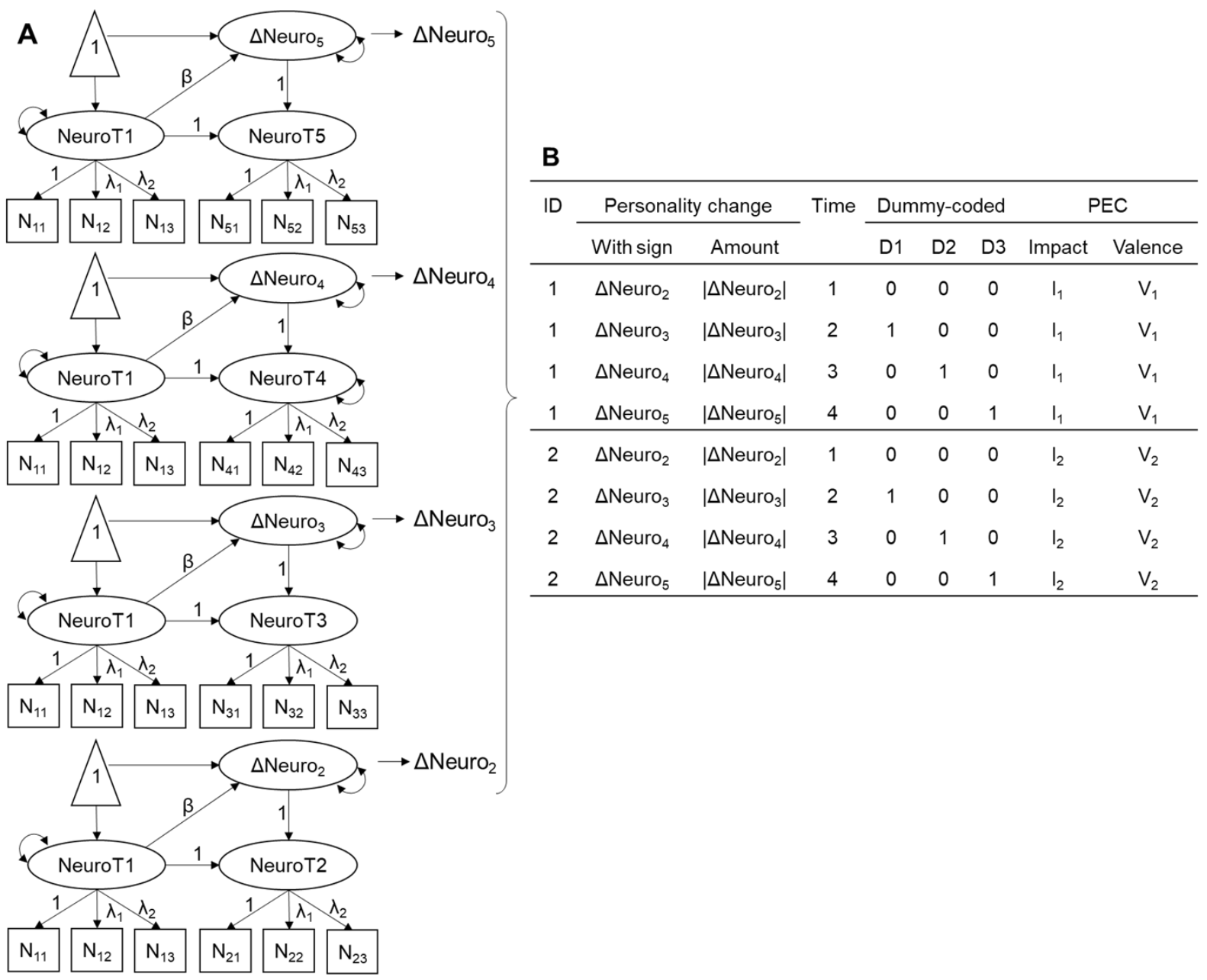

Note. Panel A: Illustration of the latent change score models to estimate within-person personality trait change variables $\left(\Delta \mathrm{Neuro}_{\mathrm{t}}\right)$. For each personality trait, we estimated four latent change score models: Each using the T1 data as pre-event personality assessment (NeuroT1) and one of the other measurement occasions as post-event personality assessment (NeuroT2 to NeuroT5). Intercepts of indicators, residual variances, and covariances are not depicted. Panel B: Data structure for multilevel models. Within-person personality trait change scores with sign or their absolute value (= amount) served as dependent variables in multilevel models. Time (dummy-coded as depicted), perceived event characteristics (only valence and impact depicted), and their cross-level interaction (not depicted) served as predictors. $\mathrm{PEC}=$ perceived event characteristic. 


\section{Figure 2}

Change in Neuroticism and Agreeableness Compared to the Pre-event Personality

Assessment for Events Perceived as Positive and Events Perceived as Negative
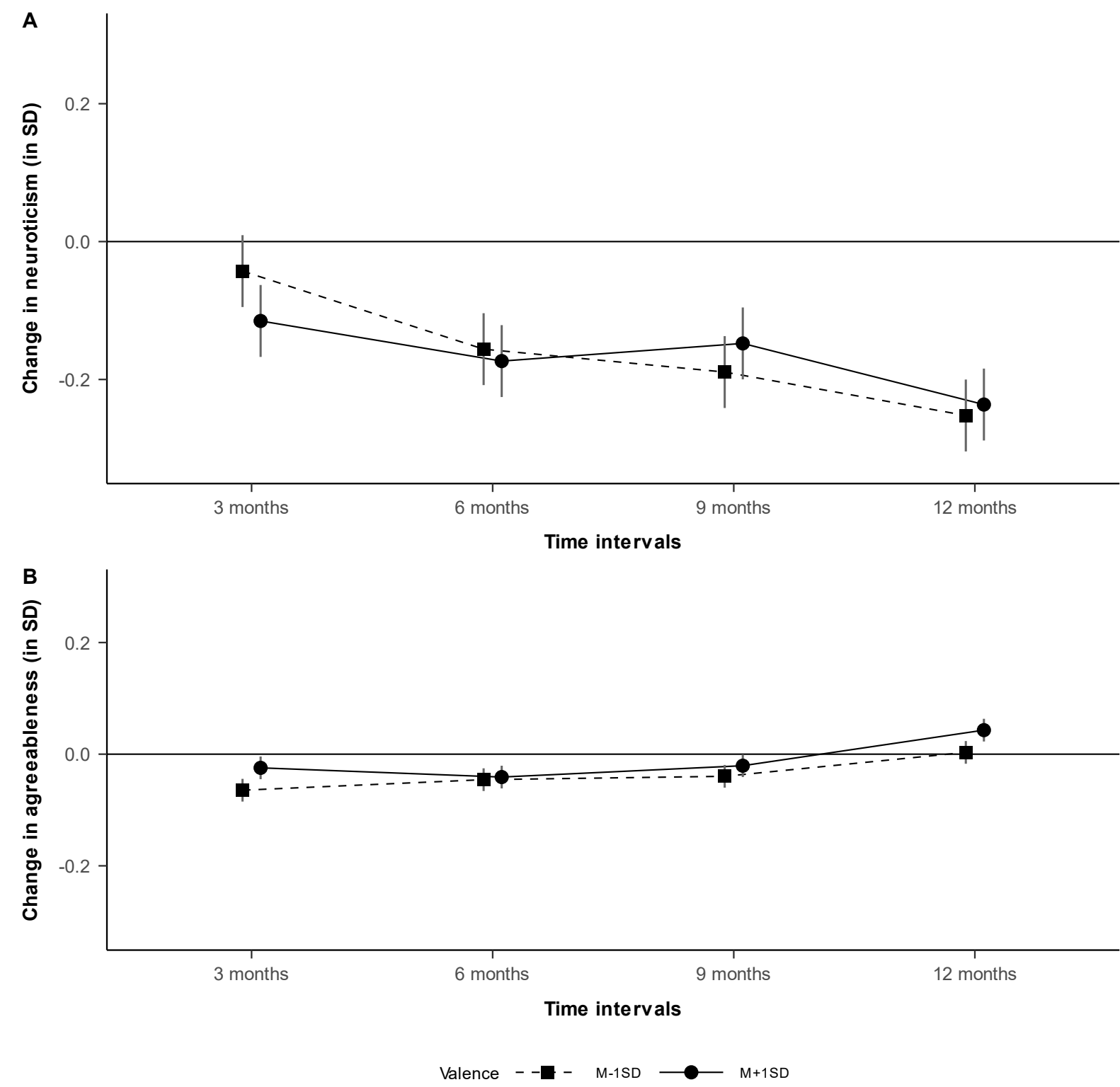

Note. Panel A: Change in neuroticism compared to pre-event personality assessments for positive events (valence: $M+1 S D$ ) and negative events (valence: $M-1 S D$ ). Over 3 months, positive perceived valence is associated with stronger decreases in neuroticism, over 12 months positive perceived valence was associated with smaller decreases in neuroticism. Whiskers indicate the $95 \%$ confidence interval for the estimated adjusted means. Panel B: Change in agreeableness compared to pre-event personality assessments for positive events (valence: $M+1 S D$ ) and negative events (valence: $M-1 S D$ ). Positive events lead to more positive changes in agreeableness, but the strength of this association is changing over time. Whiskers indicate the $95 \%$ confidence interval for the estimated adjusted means. 